question whether "the laws of physics are, like those in the statute books, of the kind that make for order" (p. 23). To this question, which I shall try to show is unintelligible, Kapp returns a negative answer, on the ground that, strictly speaking, there are no laws in Nature but only the definitions and conventions established by scientists. "The precision with which experiments are repeatable does not prove that it is in the nature of matter to behave in an orderly manner but only that it is in the nature of scientists to do so" (p. 45). And again: "The place of the laws of physics, we are led to conclude, is not in the world of physical reality but in the world of scientific methodology" (p. 62, Appendix). In passing, it might be observed that from this duplication of 'worlds' one can only conclude that so far as Kapp is concerned, Carnap's "Logical Syntax of Language" and Stebbing's "Philosophy and the Physicists" have been written in vain.

The problem of whether the laws of the natural sciences 'make for order' can arise, it seems to me, only as the result of a failure to recognize the ambiguity of the phrases "law" and "law and order". The traffic laws impose orderly conduct on motorists and others, and sometimes these "statute book laws", to use Kapp's somewhat unhappy phrase, may be difficult to enforce, as in Cyprus at the present time, in which case 'the rule of law' breaks down. But this does not mean that the phenomena in question become in any way unintelligible or unpredictable from the scientific standpoint. The reason for this is that 'statute book laws' are of a fundamentally different kind from those established by the sciences. The former are prescriptive rules which coerce human beings to behave in certain ways because sanctions are attached to them. Of an essentially similar kind are social rules and conventions. The laws of science (including, pace Kapp, those of biology) are entirely unlike these, for they are descriptive of the actual behaviour of the subject-matter in question, whether it be human, animal or material. Hence the laws of science do not 'make for' or impose order, for only prescriptive laws are capable of this; rather, they merely record the orderly relations which obtain between events. It is worth pointing out, incidentally, that in this distinction between prescriptive and descriptive laws, first clarified by Schlick, one can find the solution, or rather the resolution, of the problem of the freedom of the will.

In the seventeenth and eighteenth centuries this issue was somewhat bedevilled by certain theorists who represented the descriptive laws of Nature (often spelt with capitals) as prescriptive laws imposed by God on the Creation. This leads to the idea that the particles of a gas are 'governed' by Boyle's Law in the same kind of way that we are governed by the income tax laws. All this, of course, arises only from a failure to notice the different senses in which words like 'govern' and 'obey' are used. If Kapp had considered this, he could scarcely have employed language like: "Only on the reason why a particle of matter implicitly obeys the laws of physics may there be difference of opinion between a theologian and his atheistic opponent. The theologian might say it was because matter does not possess free will and cannot therefore sin against God's moral law. The atheist might object that the laws of physics were not ordained by God but by Nature and that a particle of matter obeys them implicitly because it is made in Nature's image and cannot do otherwise" (p. 28). The essential point is that the laws of Nature were not ordained by anybody, so that fortunately we do not have to speculate as to what can be meant by saying that something is 'made in Nature's image'. I conclude that Kapp is right in denying that scientific laws are prescriptive, but that his reasons for this are not convincing because he fails to see that there are perfectly good laws of another, that is, descriptive, kind. If this is admitted, then it appears that Kapp's notion of order, as it concerns the natural sciences, is misconceived, and so are his attempts to find its source in 'diathetes'.

C. K. Grant

\section{CENTENARY OF THE FORMER SCOTTISH METEOROLOGICAL SOCIETY}

$\mathrm{T}$ HE year 1855 saw the foundation of the Meteorological Office and the Scottish Meteorological Society, both as a result of the international conference on the meteorology of the sea held at Brussels in 1853, and the centenary of the Society's foundation was celebrated at a meeting of the Scottish centre of the Royal Meteorological Society held in Edinburgh on October 28. The principal address was delivered by Sir Ernest Wedderburn, honorary secretary of the Scottish Meteorological Society during 1909-20 and now vice-president for Scotland of the Royal Meteorological Society, and a summary of the address has been published in the November number of Weather.

Sir Ernest began by pointing out that it was Sir Henry James, then of the Scottish Ordnance Board, who proposed the formation of the Society as the best means of making available for public use the meteorological observations held by the Northern Lights. The first Council included Thomas Stevenson, designer of the Stevenson thermometer screen, and the first secretary, Dr. Stark, organized on a standard basis the work of seventy voluntary observers in Scotland and the subsequent publication of their observations by the Registrar-General. Unfortunately their preparation for publication soon had to be given up and was performed by the Astronomer-Royal for Scotland from 1858 until 1893 , when it returned to the Society. In 1860, Alexander Buchan, later famous for his world climatological atlas and his work on the climate of Edinburgh, was appointed secretary, and he soon made his influence felt by arranging in 1864 for the publication of the Society's Journal, which flourished until 1920. He represented the Society at the Leipzig conference of 1872 and, with the Director of the Meteorological Office, the British Government at the Vienna conference of 1873 which did much to draw up an international code of practice in meteorological observing.

Interest in observations at high levels began early in the Society's life, and before 1870 three stations were in operation at above a thousand feet. The most famous single work of the Society, the making of observations on the summit of Ben Nevis, was first mooted in 1877 ; the observatory on the summit was opened on November 28, 1883, and hourly observations were begun and telegraphed to the Meteorological Office in London over a line laid down the mountain. In 1883, too, the Society set up a marine research station at Granton, at which Dr. R. H. Mill began his meteorological career. 
Some government grant was received to assist the Society's work, but by the early years of this century the Society had been financially exhausted by the efforts to maintain the Ben Nevis observatory, which had, unhappily, to be closed in 1904. Negotiations with the Government resulted in 1912 in the granting of an annual sum of $£ 350$ from the Meteorological Office on condition the Society maintained an office in Edinburgh to provide for public service under the guidance of a committee, of which Sir Napier Shaw, director of the Office, was appointed chairman. Financial difficulties after the First World War led in 1920 to the complete taking over by the Meteorological Office of the Society's office and its public responsibilities, and at the same time an official Meteorological Advisory Committee for Scotland was set up with the director of the Office as chairman and a membership of representatives of the Scottish universities, learned societies and government departments.

The purpose of the Society, to establish meteorological work in Scotland on a permanent and comprehensive basis, having been achieved, the Society amalgamated in 1921 with the Royal Meteorological Society, which since 1944 has had as one of its honorary officers a secretary, more recently a vice-president, for Scotland. The balance of the funds was used to found the Royal Meteorological Society's Buchan Prize for meteorological research. Meetings of the Royal Meteorological Society were held in Scotland in 1921 and 1954, and a flourishing Scottish Centre was formed in 1946. Some famous names in meteorology connected with the Scottish Meteorological Society have been mentioned. To them may perhaps be added that of C. K. M. Douglas, who joined the Society in 1916 and published his first paper, on weather observations from aircraft, in the Journal the same year.

\section{INTERNATIONAL REVIEW OF EDUCATION}

$\mathrm{T}$

HE problems of educational theory and practice, of educational psychology and sociology, of education in home, school and society, have become, more than ever before, matters of international concern. National educational systems and national educational ideas can no longer safely be developed without contact with educational thought and action elsewhere in the world. The maintenance of cultural life has ceased to be something to be guided by ideals purely national in scope.

For these reasons a new educational journal designed to provide an international forum and to promote international exchange of information does not require extended justification. The International Review of Education has been launched on behalf of the Unesco Institute of Education, Hamburg, and edited by Karl W. Bigelow of New York, Roger Gal of Paris, M. J. Langeveld of Utrecht, Walther Merck of Hamburg and Friedrich Schneider of Munich. Editorial consultants have been appointed in various countries throughout tine world and include such well-known names as Prof. C. H. Dobinson, Prof. M. U. C. Jeffreys and Prof. F. J. Schonell.

One aim of the new journal will be to inform readers as to educational theory and practice in various countries. Another-and perhaps the more important-will be to explore the extent to which such ideas and activities have elements of validity that transcend national boundaries. Such exploration will, of course, require continuing discussion and debate.

In pursuance of its aims the Review hopes to develop an ever-strengthening chain of contacts with educational research and training centres throughout the world. Systematic attention will also be paid to international educational conferences and congresses, as well as those of more limited scope which possess special international interest. From the torrent of educational publications appearing everywhere it is the intention to select those of outstanding extranational significance for critical examination.

The first four numbers of the journal have now appeared, and each contains articles in English, French and German; articles in one of these languages contain useful summaries in the other two. Besides articles by leading English educationists, the first volume of the journal contains a valuable account of the reforms in the French educational system since the War; a bird's-eye view of education in India; a description of educational reform and its problems in post-war Japan; two articles of different points of view on nationalism and internationalism; a survey of political education in France, Great Britain, Germany and the United States; a penetrating inquiry into the state of American education and its relation to politics; a comparison between "le français élémentaire" and basic English which suggests the latter may be too basic ; and an interesting account of the way vocational training in Germany has been humanized.

\section{SOURCES OF ANIMAL BEHAVIOUR}

TN his inaugural address, delivered on May 5, 1955, at University College, London, and recently published*, Prof. G. P. Wells has drawn forcible attention to the importance of spontaneous rhythms in animal behaviour. His analytical studies of the lugworm Arenicola over the past twenty years have shown how little the normal behaviour of this worm seems to depend on the reflexes of a passive animal and how much depends on inherent rhythmic activity. Burrowing, feeding, defæcation and respiration are controlled by 'physiological clocks'. 'There is rhythmic activity originating from the osophagus, and this itself recurs in outbursts controlled by rhythms of a higher order.

In any species there are many patterns of these rhythms, and the animal may pass abruptly from one pattern to another. These patterns vary with the species; and the different patterns of rhythms are recognizably characteristic of each species, quite as much as are the anatomical characters by which they are distinguished systematically.

To illustrate the generality of rhythmic patterns, Prof. Wells shows that, just as in his Arenicola, much jecent work on the behaviour of birds suggests that this is governed by a variety of spontaneous rhythms - that is, regular activity not directly related to environmental stimuli. Rhythmic outbursts of song, feeding and reproductive cycles of behaviour recall the spontaneous rhythms of the worms. It is true that bird behaviour differs from worm behaviour in

* The Sources of Animal Behaviour. (An Inaugural Lecture delivered at University College, London, 5 May, 1955.) By Prof. G. P. Wells. 